Sharif University of Technology
Scientia Iranica
SCIENTIA
IRAN ICA
http://scientiairanica.sharif.edu

\title{
Flexural optimization of slag-based geopolymer concrete beams modified with corn cob ash
}

\author{
S. Oyebisi ${ }^{a, *}$, H. Owamah ${ }^{\mathrm{b}}$, and A. Ede ${ }^{\mathrm{a}}$ \\ a. Department of Civil Engineering, Covenant University, PMB 1023, Km 10, Idiroko Road, Ota, Nigeria. \\ b. Department of Civil and Environmental Engineering, Delta State University, Oleh Campus, Abraka, Delta State, Nigeria.
}

Received 21 November 2020; received in revised form 6 February 2021; accepted 12 April 2021

\author{
KEYWORDS \\ Pozzolan; \\ Cement; \\ Compressive strength; \\ Flexural strength; \\ Modelling; \\ Optimization.
}

\begin{abstract}
The present study investigates the flexural strength of Geopolymer Concrete (GPC) beams produced by Ground Granulated Blast Furnace Slag (GGBFS) and Corn Cob Ash (CCA). In the Design Of Experiment (DOE), Box-Behnken Design (BBD) of Response Surface Methodology (RSM) was used to optimize the strength. GGBFS was replaced at 0,20 , and 40 wt. $\%$ of CCA. The mixes were activated with 14 molar concentration (14 M) of both sodium silicate $\left(\mathrm{Na}_{2} \mathrm{SiO}_{3}\right)$ and sodium hydroxide $(\mathrm{NaOH})$ solutions. The mix design properties such as alkaline liquid-to-binder ratio, binder-to-aggregate ratio, binder ratio, and curing time were statistically employed as continuous (independent) variables to optimize the response factor (flexural strength). Compared to the control sample (Portland cement concrete), GPC exhibited higher compressive and flexural strengths at up to 40 wt.\% of CCA replacement. The models predicted the response of flexural strength with the variability of less than $5 \%$. Moreover, the correlation between the experimental and optimized flexural strengths yielded high precision with $99.6 \%$ " $R$ ". Therefore, the response models in this study would be advantageous in optimization of mix design proportions to obtain the target flexural strength of GPC beams produced by GGBFS and CCA.
\end{abstract}

(C) 2021 Sharif University of Technology. All rights reserved.

\section{Introduction}

In recent years, Geopolymer Concrete (GPC) has emerged as the eco-friendly and sustainable concrete. Geopolymer concrete utilizes Supplementary Cementitious Materials (SCMs) as the source materials for its production and it exhibits higher mechanical strength [1] and excellent durability properties [2] than Portland Cement Concrete (PCC). Supplementary cementitious materials have received extensive attention by researchers that have successfully applied them to the construction of civil engineering infrastruc-

*. Corresponding author. Tel.: +2347030110003

E-mail address: solomon.oyebisi@covenantuniversity.edu.ng (S. Oyebisi)

doi: $10.24200 /$ sci.2021.57211.5120 ture to replace Portland Cement (PC) utilization [3]. Moreover, reduction of environmental pollution, global warming, and sustainability problems has received international attention. Many researchers have valorized agro-industrial products such as Ground Granulated Blast Furnace Slag (GGBFS) [4], Corn Cob Ash (CCA) [5,6], metakaolin [7], fly ash, and Rice Husk Ash (RSA) [8,9] as excellent PC alternatives to sustainable products, infrastructure, and development. Oyebisi et al. [6] investigated the mechanical properties, microstructural behavior, and mineralogical phases of GGBFS-based GPC incorporating CCA at 0-100 wt.\% CCA under ambient curing conditions [6]. The results indicated that up to $40 \mathrm{wt} . \%$ of $\mathrm{CCA}$ replacement exhibited higher strength than PCC. The results also showed the possibility of blending CCA with GGBFS for GPC production in ambient conditions for structural application. Furthermore, an about 80-90\% 
reduction of $\mathrm{CO}_{2}$ emissions per ton and $43-59 \%$ reduction of energy needs (MJ/ton) were observed during geopolymer cement production compared with PC [10].

Different parameters such as chemical compositions of source materials, types and concentrations of alkaline solutions, water content, and curing temperatures can influence the properties of geopolymer mixes [10]. Following the traditional experimental design method, a large number of experiments are required to evaluate the influence of different parameters at various levels on the GPC properties which are expensive and time consuming. However, an appropriate Design Of Experiment (DOE) can be used to evaluate the effects of these factors with a small number of experiments [11]. Moreover, the proportion of concrete constituents is a vital aspect of concrete technology because it ensures quality, safety, and economy. The concrete mix proportion is accomplished by application of specific parameters and appropriate procedure to select the best composition of constituents and achieve the desired goals or properties. The ultimate objective is to minimize the required effort and maximize the expected benefit [11]. Therefore, the needed action or the desired use in any practical circumstance can be termed as optimization that evaluates a function's conditions, thus minimizing or maximizing the values [11].

A beam element in the structural system is often subject to flexural bending. Therefore, high flexural strength is required for a structural beam to resist the bending failure. Apart from being a flexural member, a beam is designed to withstand ultimate bending moments, shear forces, and torsional members, if any. In most cases, the design of concrete beams is governed by deflection rather than strength [12], indicating that the deflection of a concrete beam depends on its flexural strength. The deflection of concrete beams is influenced by tension and compression reinforcements, stress level, concrete size and age, aggregate properties and mineralogy, water content, and curing conditions of concrete samples [12].

Response Surface Methodology (RSM) is a statistical and analytical method that examines the effect of a set of quantitative experimental variables of factors on response [13]. RSM is usually employed to identify a set of vital elements (operating conditions) generating the "best" response [13]. Further, RSM models a relationship between the quantitative factors and the response. On the contrary, Box-Behnken Design (BBD) is a response surface three-level design in which all the design points are either at the center of the design or centered on the edges of the cube, equidistant from the center [13]. Unlike the Central Composite Design (CCD) of RSM, BBD allows an efficient estimation of quadratic terms in a regression model and consists of fewer design points, hence less expensive to run [14]. Moreover, it ensures that all design points fall within the safe operating limits (within the nominal high and low levels) for the process [13].

Alsanusi and Bentaher [15] predicted the compressive strength of concrete from early age test result using BBD. The results indicated that the developed models could predict the required compressive strength of concrete from early ages. Dai et al. [16] optimized the mix proportion of cement paste backfill materials via $B B D$. The experimental findings were indicative of the feasibility of producing the industrial standard backfilling materials. Moreover, Liu et al. [17] evaluated the effect of mix proportion parameters on Basalt Fiber Reactive Powder Concrete (BFRPC) through the BBD model. The experimental results also showed that the silica fume-to-cement ratio was a significant factor for BFRPC and it also had remarkable interaction with basalt fiber content, sand-to-binder and waterto-binder ratios on the fluidity, compressive, and flexural strengths of BFRPC. Optimization of the alkaliactivated mortar incorporating GGBFS and natural pozzolan was conducted through Taguchi method. The obtained results indicated that the flow and strength values for the materials could be optimized using the DOE, as mentioned earlier [11]. However, Ramkumar et al. [18] employed the CCD of the RSM to optimize the mechanical strengths of fly ash-based GPC. It was concluded that the RSM validated the influence factors with an average difference of less than $5 \%$, hence acceptable. However, the optimization of GPC beams modified by GGBFS and CCA is a novel development as no study has been conducted on optimizing its flexural strength through RSM-BBD.

In this respect, the present study aims to optimize the flexural strength of GPC beams produced by both GGBFS and CCA. To this end, the BBD model of RSM was employed to arrive at an optimum combination of mix parameters of GPC. The selected mix parameters were CCA-to-GGBFS ratio, alkaline liquid-to-binder ratio, binder-to-aggregate ratio, 14 molar concentrations of $\mathrm{NaOH}$ and $\mathrm{Na}_{2} \mathrm{SiO}_{3}$ solutions, and curing times and mix design proportions. In addition, the flexural strengths of M 25-40 concrete grades were selected as the target strengths. The GPC samples were cured under ambient conditions $\left(23 \pm 5^{\circ} \mathrm{C}, 65 \%\right.$ relative humidity), eliminating the heat curing conditions, which was not feasible for field application. Ultimately, the developed models can be applied to predict the flexural strength of geopolymer concrete incorporating natural pozzolans in a building sector, thus reducing cost, energy, and time while conducting laboratory works.

\section{Materials and methods}

\subsection{Materials}

GGBFS, corncob, and 42.5R Portland Limestone Cement (PLC) were locally sourced and used as precursor 


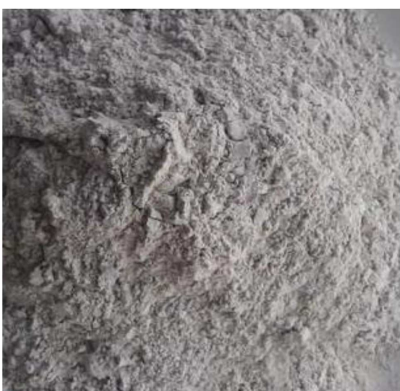

(a)

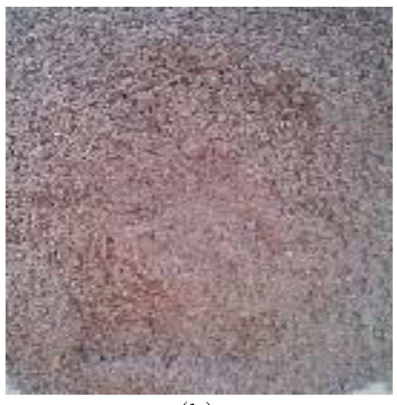

(b)
Figure 1. Source materials used: (a) Ground Granulated Blast Furnace Slag (GGBFS) and (b) Corn Cob Ash (CCA).

Table 1. Physical properties of the precursor materials used.

\begin{tabular}{lccc}
\hline \multicolumn{1}{c}{ Properties } & GGBFS & CCA & PLC \\
\hline SG $\left(\mathrm{g} / \mathrm{cm}^{3}\right)$ & 2.90 & 2.44 & 3.15 \\
Fineness $(\%)$ & 7.6 & 7.8 & 7.50 \\
SSA $\left(\mathrm{m}^{2} / \mathrm{kg}\right)$ & 420 & 505 & 375 \\
Mean particle size $(\mu \mathrm{m})$ & 20.68 & 19.14 & 23.45 \\
\hline
\end{tabular}

materials. Corn cob was valorized, and 25 wt.\% of corncobs was obtained as CCA. Therefore, both GGBFS and CCA, as shown in Figure 1, were used as the source materials to produce GPC, while PLC was used as a binder to produce PCC (control concrete). The Specific Gravity (SG) of the precursor materials was obtained following the BS EN [19] procedure through kerosene and SG bottle, the results of which are presented in Table 1. Furthermore, the fineness and Specific Surface Area (SSA) of the materials were obtained based on BS EN [20] procedure, the results of which are given in Table 1. Moreover, the Particle Size Distribution (PSD) of the materials was analyzed over

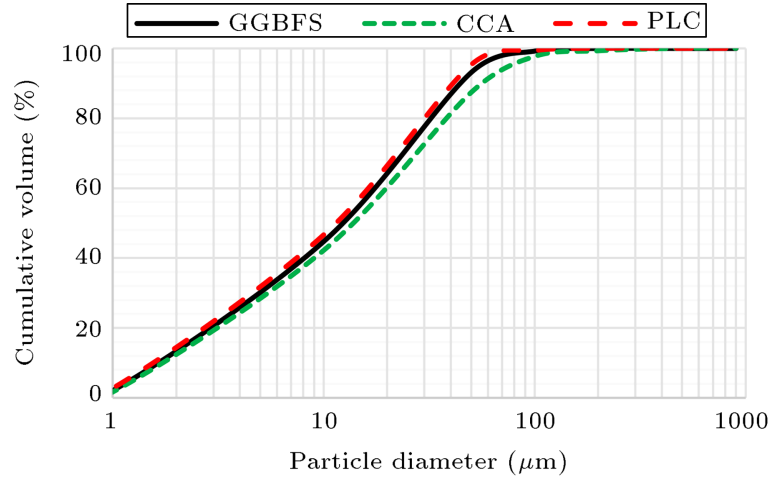

Figure 2. The cumulative Particle Size Distribution (PSD) of the precursor materials used.

the range size of $0.5-900 \mu \mathrm{m}$ using Laser diffraction, Model Beckman Coulter LS-100, as shown in Figure 2. The results of the mean particle size are presented in Table 1. According to this table, more volume of both CCA and GGBFS would be required when mixed with PLC due to their lower SG and higher fineness than PLC. In addition, both CCA and GGBFS would favorably react with the cement Portlandite and alkaline environment due to their higher SSA and lower particle size than that of PLC [7]. The chemical compositions of the precursor materials were analyzed using XRF spectrophotometer machine, Philips PW1800. The obtained results are shown in Table 2 .

The characterizations of the used source materials were analyzed using Scanning Electron Microscopy (SEM), JEOL 7000600. All images were observed at $4000 \times$ magnification in a high vacuum from the working distance ranging from 8.3 to $10.6 \mathrm{~mm}$ at a constant $15 \mathrm{kV}$ accelerated voltage. The results are shown in Figure 3. The GGBFS particles, as depicted in Figure 3(a), are characterized by an amorphous shape with an uneven surface. On the contrary, the

Table 2. Chemical compositions of the precursor materials used.

\begin{tabular}{|c|c|c|c|c|c|c|}
\hline $\begin{array}{c}\text { Oxide } \\
\text { composition } \\
(\%)\end{array}$ & GGBFS & $\begin{array}{c}\text { BS EN }[21] \\
\text { requirements for } \\
\text { GGBFS }\end{array}$ & CCA & $\begin{array}{c}\text { BS EN }[22] \\
\text { requirements for } \\
\text { CCA }\end{array}$ & PLC & $\begin{array}{c}\text { BS EN }[23] \\
\text { requirements for } \\
\text { PLC }\end{array}$ \\
\hline $\mathrm{CaO}$ & 36.52 & $32-38$ & 12.62 & - & 64.9 & $61-69$ \\
\hline $\mathrm{SiO}_{2}$ & 35.77 & $32-38$ & 60.5 & $\begin{array}{l}\mathrm{SiO}_{2}+\mathrm{Al}_{2} \mathrm{O}_{3}+ \\
\mathrm{Fe}_{2} \mathrm{O}_{3}=70 \mathrm{~min}\end{array}$ & 21.6 & $18-24$ \\
\hline $\mathrm{Al}_{2} \mathrm{O}_{3}$ & 14.11 & $14-19$ & 8.78 & & 5.85 & $2.6-8.0$ \\
\hline $\mathrm{Fe}_{2} \mathrm{O}_{3}$ & 0.92 & $0.72-2.0$ & 9.13 & & 2.78 & $1.5-7.0$ \\
\hline $\mathrm{MgO}$ & 9.45 & $6-10$ & 1.23 & $4.0 \max$ & 1.42 & $0.5-4.0$ \\
\hline $\mathrm{K}_{2} \mathrm{O}$ & 0.52 & $0.1-0.7$ & 1.25 & - & 0.72 & $0.2-1.0$ \\
\hline $\mathrm{Na}_{2} \mathrm{O}$ & 0.3 & $0.2-0.7$ & 0.65 & $5.0 \max$ & 0.14 & - \\
\hline $\mathrm{SO}_{3}$ & 1.08 & $0.2-1.0$ & 1.25 & $3.0 \max$ & 2.03 & $0.2-4.0$ \\
\hline $\mathrm{LOI}^{\mathrm{a}}$ & 1.32 & $0.5-3.0$ & 2.89 & $10.0 \max$ & 1.38 & $5.0 \max$ \\
\hline
\end{tabular}

${ }^{\mathrm{a}} \mathrm{LOI}$ is loss of ignition at $800^{\circ} \mathrm{C}$. 


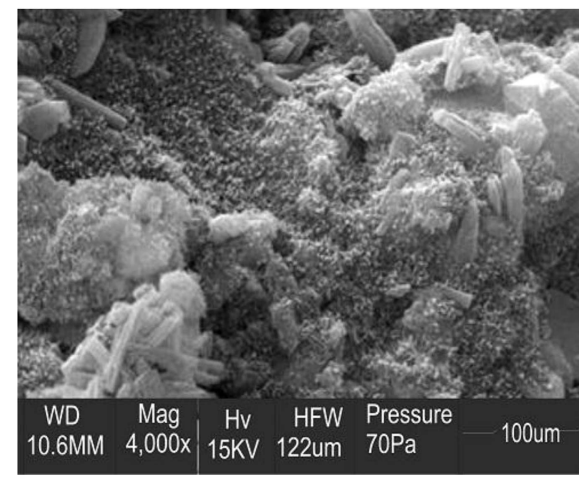

(a)

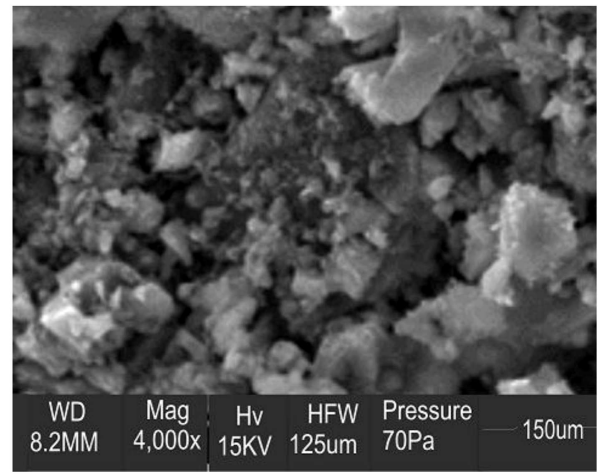

(b)

Figure 3. Scanning Electron Microscopy (SEM) micrographs on source materials: (a) Ground Granulated Blast Furnace Slag (GGBFS) and (b) Corn Cob Ash (CCA).

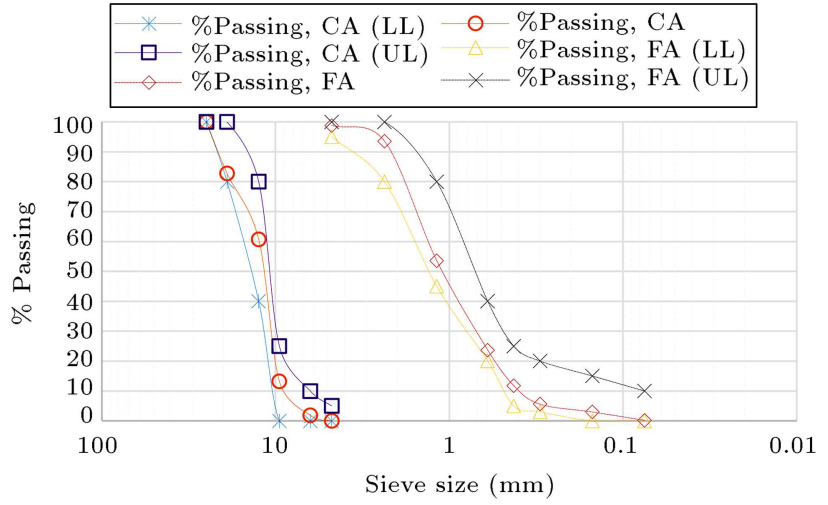

Figure 4. Particle Size Distribution (PSD) of CA and FA used.

internal structure of CCA particles, as shown in Figure $3(\mathrm{~b})$, is irregular in shape with a wrinkled surface. Hence, these results are consistent with the findings of other similar studies such that GGBFS reveals an amorphous form with sharp needles, while pozzolan, CCA in this case, indicates irregular shape with hollow pores [12].

Aggregates, fine aggregates (sharp sand $\leq 4.5$ $\mathrm{mm}$ ), and coarse aggregates (granite $\leq 12.5 \mathrm{~mm}$ size) were locally sourced and used. As shown in Figure 4, PSD was conducted on the aggregates based on BS EN [24] procedure. Moreover, SG and Water Absorption (WA) were determined in line with BS EN [24] established method. According to the results, SG and WA for both fine and coarse aggregates were 2.60 and $2.64 \mathrm{~g} / \mathrm{cm}^{3}$ and 0.7 and $0.8 \%$, respectively. Besides, Moisture Content (MC) was determined based on BS EN [24] procedure, which was calculated as 0.3 and $0.2 \%$ for both fine and coerce aggregates, respectively.

The alkaline activators including $\mathrm{NaOH}$ pellets ( $99 \%$ purity) and $\mathrm{Na}_{2} \mathrm{SiO}_{3}$ gel were sourced in Lagos, Nigeria. $\mathrm{Na}_{2} \mathrm{SiO}_{3}$ gel (SS) consists of $\mathrm{Na}_{2} \mathrm{O}, \mathrm{SiO}_{2}$, and $\mathrm{H}_{2} \mathrm{O}$ with $9.4,30.1$, and $60.5 \%$ respectively, with the $\mathrm{SiO}_{2} / \mathrm{Na}_{2} \mathrm{O}$ weight ratio of 3.20 and $\mathrm{SG}$ of $1.40 \mathrm{~g} / \mathrm{cm}^{3}$ at $20^{\circ} \mathrm{C}$. Following the application of chemistry pro- cedures of Rajamane and Jeyalakshmi [25], $400 \mathrm{~g}$ of $\mathrm{NaOH}$ pellets were measured and dissolved in $600 \mathrm{~g}$ of clean water to prepare $14 \mathrm{M}$ activator using $\mathrm{Na}_{2} \mathrm{SiO}_{3}$ to $\mathrm{NaOH}$ solutions (SS/SH) with a ratio of $2.5: 1$. The activator and proportion were selected in compliance with those of other relevant studies $[6,26]$ such that $14 \mathrm{M}$ activator yielded the highest mechanical strength among 12 and $16 \mathrm{M}$ as well as PCC. Moreover, the ratio of 2.5:1 for $\mathrm{Na}_{2} \mathrm{SiO}_{3}$-to- $\mathrm{NaOH}$ solutions exhibited higher mechanical performance than those of 1.5:1, 2:1, and $3: 1$ on days $7,28,59$, and 90 of curing [6].

\subsection{Mix design quantities}

A 0-40 wt.\% GGBFS content was selected and replaced by $\mathrm{CCA}$ in accordance with the findings of similar studies $[6,26]$ to ensure the target strength of the structural applications. The mixes were designed in accordance with BS EN [27] procedure to achieve the concrete target strengths of 25, 30, and $40 \mathrm{MPa}$ for grades of M 25-40, respectively, due to their general applications in the construction sector. Consequently, GGBFS was replaced by CCA content at 0,20 , and $40 \%$ for all concrete grades. The results of mix design proportions are presented in Tables 3-5 for M 25, 30, and 40, respectively.

\subsection{Mix preparation, casting, and curing}

As shown in Figure 5, the mix was prepared in accordance with the BS [28] and BS EN [29] procedures using a standard cube $150 \mathrm{~mm}^{3}$ for compression and a standard beam of $150 \mathrm{~mm}$ deep and $750 \mathrm{~mm}$ long for flexure. The samples were cured under ambient conditions $\left(23 \pm 5^{\circ} \mathrm{C}\right.$ and $\left.65 \% \mathrm{RH}\right)$ and tested on days 28,59 , and 90 .

\subsection{Compressive and flexural strength tests and analysis}

The compressive and flexural strengths were tested in accordance with the BS EN [30] and BS EN [31] procedures using the digital compressive testing machine (Model: YES-2000) and fully automatic transverse 
Table 3. Mix proportions for M $25\left(\mathrm{~kg} / \mathrm{m}^{3}\right)$.

\begin{tabular}{cccccc}
\hline Mix ID & PLC & GGBFS & CCA & NaOH solution & $\mathbf{N a}_{2} \mathbf{S i O}_{\mathbf{3}}$ gel \\
\hline K0 & 340 & 0 & 0 & 0 & 0 \\
K1 & 0 & 340 & 0 & 60 & 150 \\
K2 & 0 & 272 & 68 & 60 & 150 \\
K3 & 0 & 204 & 136 & 60 & 150 \\
\hline
\end{tabular}

Conditions: $\mathrm{FA}=715 \mathrm{~kg} / \mathrm{m}^{3} ; \mathrm{CA}=1035 \mathrm{~kg} / \mathrm{m}^{3} ;$ alkaline liquid-binder $(\mathrm{AL} / \mathrm{B})$ ratio for $\mathrm{GPC}=0.62$; water-cement $(\mathrm{w} / \mathrm{c})$ ratio for $\mathrm{PLC}=0.62$; binder-aggregate $(B / \mathrm{Agg})$ ratio $=0.19$.

Table 4. Mix proportions for M $30\left(\mathrm{~kg} / \mathrm{m}^{3}\right)$.

\begin{tabular}{cccccc}
\hline Mix ID & PLC & GGBFS & CCA & NaOH solution & $\mathbf{N a}_{2} \mathbf{S i O}_{3}$ gel \\
\hline L0 & 390 & 0 & 0 & 0 & 0 \\
L1 & 0 & 390 & 0 & 60 & 150 \\
L2 & 0 & 312 & 78 & 60 & 150 \\
L3 & 0 & 232 & 156 & 60 & 150 \\
\hline
\end{tabular}

Conditions: $\mathrm{FA}=675 \mathrm{~kg} / \mathrm{m}^{3} ; \mathrm{CA}=1031 \mathrm{~kg} / \mathrm{m}^{3} ;$ alkaline liquid-binder $(\mathrm{AL} / \mathrm{B})$ ratio for $\mathrm{GPC}=0.52$; water-cement $(\mathrm{w} / \mathrm{c})$ ratio for $\mathrm{PLC}=0.52$; binder-aggregate $(B / \mathrm{Agg})$ ratio $=0.25$.

Table 5. Mix proportions for M $40\left(\mathrm{~kg} / \mathrm{m}^{3}\right)$.

\begin{tabular}{cccccc}
\hline Mix ID & PLC & GGBFS & CCA & NaOH solution & $\mathbf{N a}_{2} \mathbf{S i O}_{3}$ gel \\
\hline M0 & 500 & 0 & 0 & 0 & 0 \\
M1 & 0 & 500 & 0 & 60 & 150 \\
M2 & 0 & 400 & 100 & 60 & 150 \\
M3 & 0 & 300 & 200 & 60 & 150 \\
\hline
\end{tabular}

Conditions: $\mathrm{FA}=585 \mathrm{~kg} / \mathrm{m}^{3} ; \mathrm{CA}=1031 \mathrm{~kg} / \mathrm{m}^{3} ;$ alkaline liquid-binder $(\mathrm{AL} / \mathrm{B})$ ratio for $\mathrm{GPC}=0.42$; water-cement $(\mathrm{w} / \mathrm{c})$ ratio for $\mathrm{PLC}=0.42$; binder-aggregate $(\mathrm{B} / \mathrm{Agg})$ ratio $=0.31$.

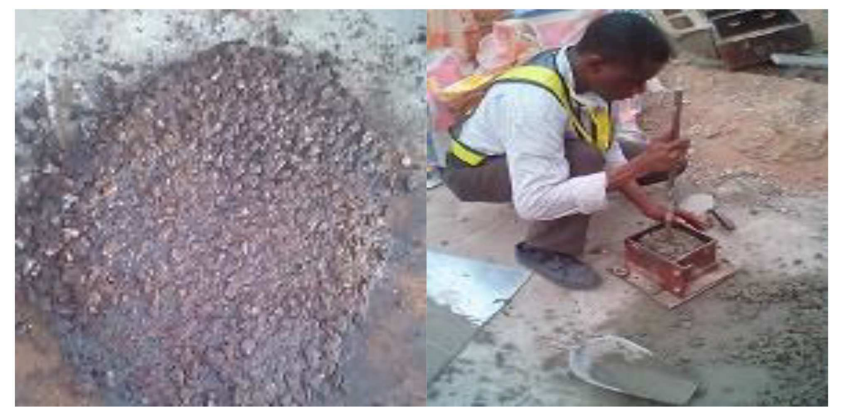

Figure 5. Mixing and casting the samples.

flexural testing machine (Model: 2A8580), as shown in Figure 6(a) and (b), respectively. The sample was crushed, and the flexural strength was determined through the relationship, as illustrated in Eq. (1).

$$
f_{r}=\frac{1.5 P l}{b d^{2}}
$$

where $f_{r}$ is flexural strength (MPa), $P$ is applied load at failure $(\mathrm{N}), l$ is distance between the supports $(\mathrm{mm})$, $b$ is concrete sample width $(\mathrm{mm})$, and $d$ is concrete sample depth $(\mathrm{mm})$.

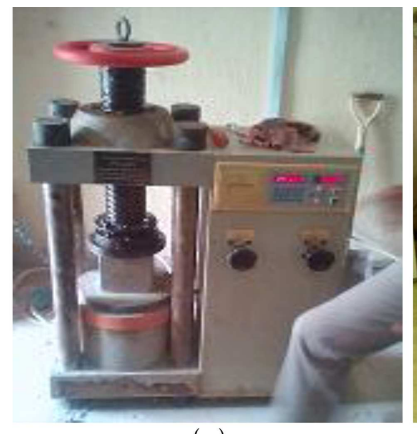

(a)

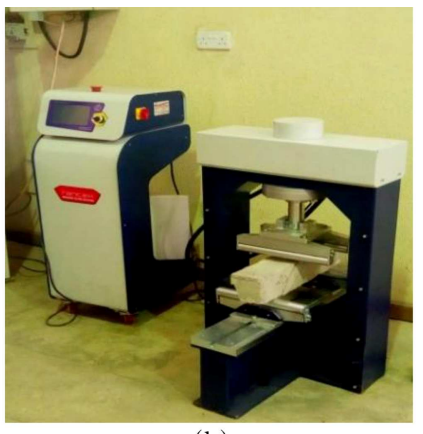

(b)
Figure 6. Strength tests: (a) Compression and (b) flexure.

\subsection{Design of Experiment (DOE)}

2.5.1. Box-Behnken Design (BBD)

The BBD of RSM were employed to evaluate the interaction between the selected continuous variables [alkaline liquid-to-binder ratio $(A l / B)$, binder-to-aggregates ratio $(B / A g g), \mathrm{CCA} /(\mathrm{CCA}+\mathrm{GGBFS})$ ratio $(C)$, and curing time $(T$, day)], response variable, and flexural strength $\left(f_{r}, \mathrm{MPa}\right)$. Minitab statistical software was engaged and the BBD was created using four different continuous variables, the results of which are shown in 
Table 6. Continuous variables at a 3-different level for Box-Behnken Design (BBD).

\begin{tabular}{lcccc}
\hline & & \multicolumn{3}{c}{ Coded values } \\
\cline { 3 - 5 } Variables & & Low & Centre & High \\
& Symbol & $\mathbf{- 1}$ & $\mathbf{0}$ & $\mathbf{+ 1}$ \\
\hline$A l / B^{\text {a }}$ & $\mathrm{A}$ & 0.42 & 0.52 & 0.62 \\
$B / A g g^{\mathrm{b}}$ & $\mathrm{B}$ & 0.19 & 0.25 & 0.31 \\
$\mathrm{CCA} /(\mathrm{CCA}+\mathrm{GGBFS})^{\mathrm{c}}$ & $\mathrm{C}$ & 0 & 0.20 & 0.40 \\
Curing time & $\mathrm{T}$ & 28 & 59 & 90 \\
\hline
\end{tabular}

a alkaline liquid to binder ratio; ${ }^{\mathrm{b}}$ binder to aggregate ratio;

${ }^{\mathrm{c}}$ corn cob ash to slag ratio.

Table 6. Therefore, the experimental run number was estimated using the illustration presented in Eq. (2) [13]:

$$
N=2 v(v-1)+c_{p},
$$

where $N$ is number of experimental runs, $v$ is total continuous variables, and $c_{p}$ is total applied central point.

Following Eq. (2), 27 experimental runs were conducted based on four continuous variables and three applied central points, as shown in Table 6. In addition, full quadratic polynomial, as illustrated in Eq. (3), accurately optimizes the relationship between the continuous and response variables, thus yielding high precision $[13,14]$.

$$
Y=a_{0}+\sum_{i=1}^{n} a_{i} x_{i}+\sum_{i=1}^{n} a_{i i} x_{i}^{2}+\sum_{i<j} a_{i j} x_{i} x_{j}
$$

where $Y$ is response variable $\left(f_{r}\right), a_{0}$ is model coefficient constant, $x_{i}, x_{j}$ is continuous variables $(A, B$, $C$, and $T), a_{i}$ is linear coefficient, $a_{i i}$ is quadratic coefficient, and $a_{i j}$ is interaction coefficient.

\subsubsection{Optimization of variables}

This study aimed to optimize the design variables by minimizing the continuous variables $(A, B, C$, and $T$ ) and maximizing the response variable $\left(f_{r}\right)$ using the optimization concept. Following this concept, the response variable or value was converted into a composite desirability function $(D)$ in the range of $0-1$, as illustrated in Eq. (4) [13,32]. The closer the composite desirability to 1 , the better the optimization [13].

$$
0 \leq D \leq 1
$$

According to Eq. (4), $D=1$ if the response value $\left(f_{r}\right)$ is at its goal or target. In addition, $D=0$ if the response value is outside an acceptable region. Moreover, the desirability is composite based on the expressions illustrated in Eqs. (5)-(7) to maximize, minimize, and make the response to be as close as possible to the target, respectively [32]. Therefore, Eqs. (5)-(7) were used to validate the results of the optimization study.

$$
\begin{aligned}
& \begin{cases}D=0 & \text { if } r \leq L \\
D=\left(r-\frac{L}{T}-L\right)^{w} & \text { if } \quad L \leq r \leq T \\
D=1 & \text { if } r \geq T\end{cases} \\
& \begin{cases}D=1 & \text { if } r \leq T \\
D=\left(r-\frac{U}{T}-U\right)^{w} & \text { if } T \leq r \leq U \\
D=0 & \text { if } r \geq U\end{cases} \\
& \begin{cases}D=\left(r-\frac{L}{T}-L\right)^{w 1} & \text { if } L \leq r \leq T \\
D=1 & \text { if } r=T \\
D=\left(r-\frac{U}{T}-U\right)^{w 2} & \text { if } T \leq r \leq U \\
D=0 & \text { if } r=L \\
D=0 & \text { if } r=U\end{cases}
\end{aligned}
$$

where $D$ is composite desirability function $(0-1), r$ is response, $L$ is lower value/limit, $U$ is upper value/limit, $T$ is target value/limit, and $w$ is weight.

\section{Results and discussion}

\subsection{Mechanical strengths}

Figure $7(\mathrm{a})-(\mathrm{c})$ present the results of compressive strength for concrete grades of 25,30, and 40, respectively. Figure $8(\mathrm{a})-(\mathrm{c})$ show the results of flexural strength for concrete grades of 25, 30, and 40, respectively. The results revealed that both compressive and flexural strengths increased upon increasing the curing age for all concrete mixtures at all concrete grades levels. There was about $3-15 \%, 2-7 \%$, and $2-8 \%$ increases in the flexural strength as the curing age increased from 28-90 days curing for M 25-40, respectively. Further, both compressive and flexural strengths increased upon increasing the GGBFS content in the mix. Unlike PCC, GPC exhibited higher compressive and flexural strength at all curing ages and concrete grades that could be attributed to the reaction between the glassy phase of GGBFS and 


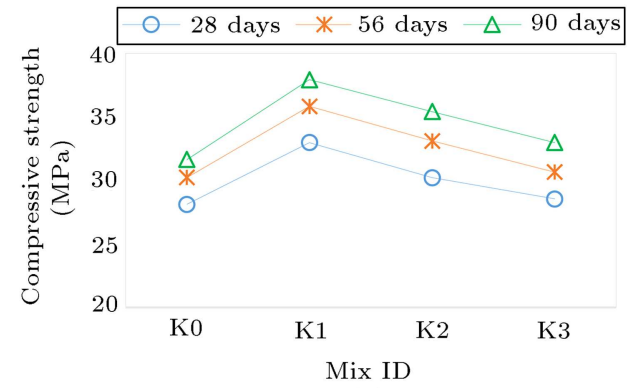

(a)

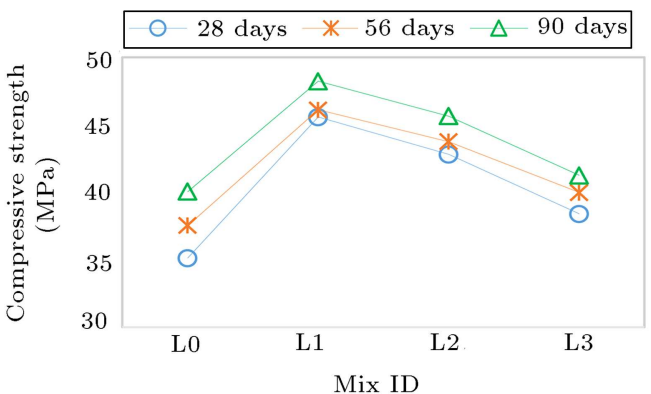

(b)

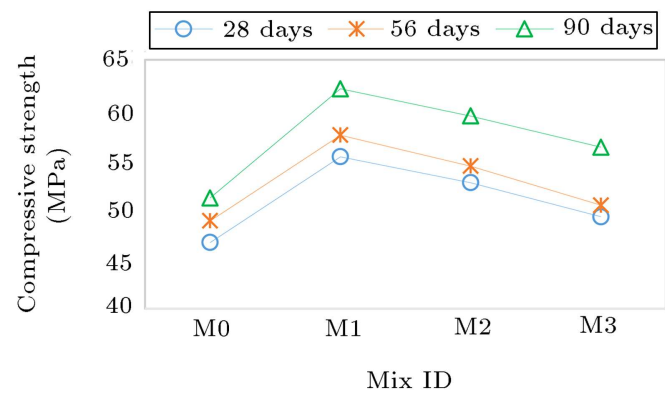

(c)

K0(100\%PLC); K1 $1(100 \%$ GGBFS $)) ; K 2(80 \% G G B F S$ $+20 \% C C A) ; K 3(60 \% G G B F S+40 \% C C A)$

Figure 7. Compressive strengths for (a) M 25, (b) M 30, and (c) M 40 .

alkaline liquid, thus resulting in the X-Ray Amorphous Aluminosilicate Gel (X-RAAG) which, according to Chen and Brouwers [33] and Khale and Chaudhary [34], contributed to the higher mechanical strength in the GPC. On the contrary, there was a gradual decrease in both compressive and flexural strength of GPC as the replacement level of $\mathrm{CCA}$ in the mix increased from 20-40 wt.\%. The gradual reduction in strength may be attributed to the reduction in aluminosilicate glassy phase of GGBFS. Therefore, the reactive presence of Calcium-Silicate-Aluminate-Hydrate (C-S-A-H) in the geopolymer paste decreased and the pores of geopolymer matrix increased, thus reducing the strength [12]. However, the partial replacement of GGBFS by $20-$ 40 wt.\% CCA met the target strength of M 25-40 at the 28-day curing age and surpassed the strength of the control sample (PCC). Statistically, on day 90 of curing, there was about $13-22 \%, 9-15 \%$, and $7-$ $14 \%$ increase in the flexural strength as the percentage

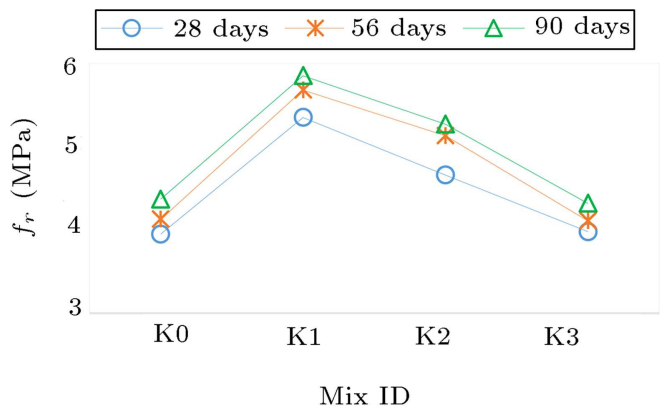

(a)

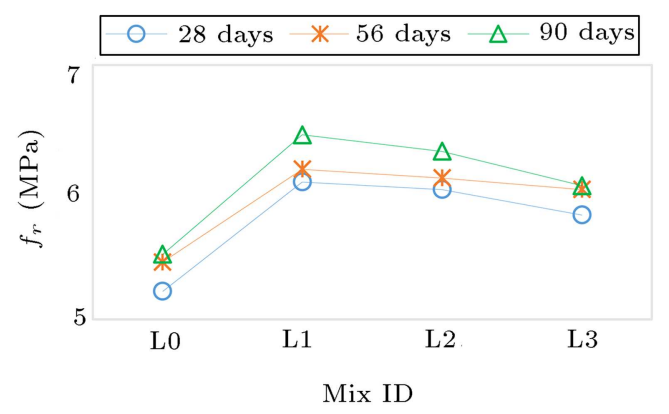

(b)

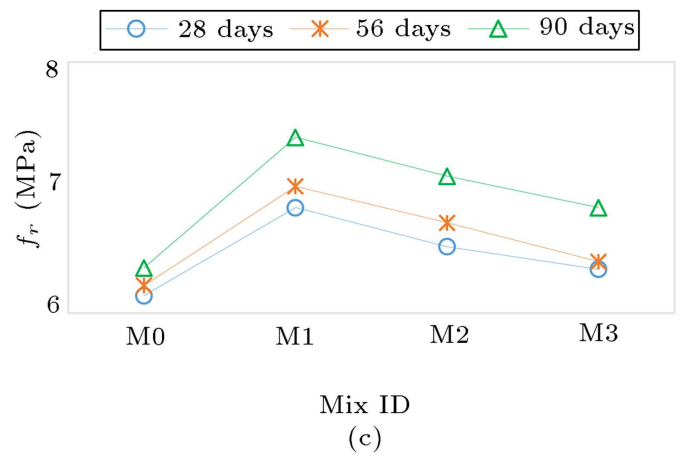

Figure 8. Flexural strengths for (a) M 25, (b) M 30, and (c) M 40 .

content of GGBFS in the mix increased from 60$100 \%$ for M 25-40, respectively, compared with PCC. The experimental results, as shown in Figure 8(a)-(c), confirmed that GPC exhibited higher resistance against bending than that of the conventional concrete (PCC). Therefore, both GGBFS and CCA can be used as natural pozzolans as an PLC alternative in the flexural strengthening of the concrete beam.

\subsection{Analysis of response surface design}

Following the creation of BBD and establishment of response surface design from data in a worksheet, as illustrated in Table 6 , the fitted model analysis results for a response surface design are presented in Table 7 . The model's accuracy and the influence of continuous variables on the flexural strength were examined by analyzing variance (ANOVA).

The regression model in Table 7 indicates that the terms in the model have a significant effect on the 
Table 7. BBD-ANOVA of the regression model.

\begin{tabular}{|c|c|c|c|c|c|}
\hline Source & DF & Adj SS & Adj MS & $F$-value & $P$-value \\
\hline Model & 11 & 21.1491 & 1.92264 & 348.25 & 0.000 \\
\hline Linear & 4 & 20.2229 & 5.05572 & 915.74 & 0.000 \\
\hline A & 1 & 1.8629 & 1.86294 & 337.43 & 0.000 \\
\hline $\mathrm{B}$ & 1 & 1.1575 & 1.15748 & 209.65 & 0.000 \\
\hline $\mathrm{C}$ & 1 & 3.1300 & 3.13005 & 566.94 & 0.000 \\
\hline $\mathrm{T}$ & 1 & 0.7820 & 0.78198 & 141.64 & 0.000 \\
\hline Square & 2 & 0.00653 & 0.0131 & 1.18 & 0.333 \\
\hline $\mathrm{C}^{2}$ & 1 & 0.0119 & 0.01185 & 2.15 & 0.164 \\
\hline $\mathrm{T}^{2}$ & 1 & 0.0012 & 0.00122 & 0.22 & 0.645 \\
\hline 2-way interaction & 5 & 1.2792 & 0.25583 & 46.34 & 0.000 \\
\hline $\mathrm{A} \times \mathrm{C}$ & 1 & 0.7869 & 0.78687 & 142.53 & 0.000 \\
\hline $\mathrm{A} \times \mathrm{T}$ & 1 & 0.0388 & 0.03876 & 7.02 & 0.018 \\
\hline $\mathrm{B} \times \mathrm{C}$ & 1 & 0.6974 & 0.69742 & 126.32 & 0.000 \\
\hline $\mathrm{B} \times \mathrm{T}$ & 1 & 0.0414 & 0.04137 & 7.49 & 0.015 \\
\hline $\mathrm{C} \times \mathrm{T}$ & 1 & 0.0113 & 0.01127 & 2.04 & 0.173 \\
\hline Error & 15 & 0.0828 & 0.00552 & & \\
\hline Total & 26 & 21.2319 & & & \\
\hline \multicolumn{6}{|c|}{$\begin{array}{l}\mathrm{DF}=\text { Degree of Freedom; Adj SS }=\text { Adjusted Sum of Square; } \\
\text { Adj MS =Adjusted Mean Square }=\text { Adj SS } / \mathrm{DF} ; \\
F \text {-value }=\text { Mean square/residual mean square; } \\
P \text {-value }=\text { Significance level compared with } \alpha \text {-value of } 0.05 \\
\text { Null hypothesis }\left(H_{o}\right): \text { If } P \text {-value } \leq \alpha \text {-value, there is a significant effect; } \\
\text { If P-value }>\alpha \text {-value, then no significant impact. }\end{array}$} \\
\hline
\end{tabular}

flexural strength because $P=0.000$, which is less than $\alpha$-level (0.05) [35]. In addition, the $P$-values for the continuous variables, $A, B, C$, and $T$ are $0.000,0.000$. 0.000 , and 0.000 , respectively, indicating the significant linear effect. The resisting performance of the concrete against bending depends on the proportions of alkaline liquid, binder and aggregate contents, and curing time. The following terms, $(A)^{2},(B)^{2}$, and $(A \times B)$, were regarded as non-significant terms and removed from the model according to the $P$-value. Moreover, according to Table 7 , the $P$-values of $0.333,0.164$, and 0.645 for the squared effects, $(C)^{2}$, and $(T)^{2}$, respectively, were higher than 0.05 , indicating that the relationship between $f_{r}$ and $C$ as well as $f_{r}$ and $T$ exhibited no significant quadratic effect. However, the $P$-values of $0.000,0.018,0.000$, and 0.0015 for the $A \times C, A \times T$, $B \times C$, and $B \times T$, respectively, were less than 0.05 , indicating a significant interaction effect. The effect of both $A$ and $B$ on the resisting performance of concrete against deflection depends on $C$ and $T$. There was still no significant interaction effect between $C \times T$ on the yield of $f_{r}$ because $P$-value $=0.173$ was higher than 0.05 . However, as shown in Table 7 , the $F$-value for all significant terms was greater than 5 , confirming that the model terms were substantial [36] to the yield of flexural strength. Finally, the model yielded no lackof-fit or pure error because both linear and interaction terms were significant, hence included in the model.
The special effect was also evaluated using the coded coefficient analysis to examine the correlational level of the continuous variables, the results of which are presented in Table 8 . According to the results, all model terms corroborated the ANOVA regression analysis, as shown in Table 7 , thus yielding a significant effect. In addition, VIF values were higher than 10 and the $P$-values were less than 0.05 . However, the squared terms of both $C \times T$ and the interaction term between $C \times T$ yielded VIF of 1.00 , indicating that the variables were not correlated [14]. As a result of the ANOVA and coded coefficient of the model, the regression model equation between the response $\left(f_{r}\right)$ and continuous variables $(A, B, C$, and $T$ ) can be illustrated, as shown in Eq. (8). The model summary yielded $S, R^{2}, R^{2}$ (adj), and $R^{2}$ (pred) as $0.0743028,99.61 \%, 99.32 \%$, and $98.66 \%$, respectively, showing that the model equation could predict the relationship between the response variable and continuous variables at $100 \%$ confidence bound. Ultimately, this developed model equation can be used to predict the flexural optimization of the concrete strength incorporated with SCMs.

$$
\begin{aligned}
f_{r}= & 24.59-23.00 A-27.10 B+151.90 C-0.221 T \\
& -1.111 C^{2}+0.000015 T^{2}-169.40 A C+0.2421 A T \\
& -262.70 B C+0.412 B T-0.00494 C T
\end{aligned}
$$


Table 8. Coded coefficient analysis of the regression model.

\begin{tabular}{ccccccc}
\hline Term & Effect & Coef. & SE coef & $\boldsymbol{T}$-value & $\boldsymbol{P}$-value & VIF \\
\hline Constant & & 5.8871 & 0.0338 & 174.41 & 0.000 & \\
A & -8.518 & -4.259 & -18.37 & 0.232 & 0.000 & 177.61 \\
B & -6.637 & -3.319 & 0.229 & -14.48 & 0.000 & 177.61 \\
$\mathrm{C}$ & -1.0220 & -0.5110 & 0.0215 & -23.81 & 0.000 & 1.50 \\
$\mathrm{~T}$ & 0.5103 & 0.2551 & 0.0214 & 11.90 & 0.000 & 1.50 \\
$\mathrm{C}^{2}$ & -0.0889 & -0.0444 & 0.0303 & -1.47 & 0.164 & 1.00 \\
$\mathrm{~T}^{2}$ & 0.0288 & 0.0144 & 0.0307 & 0.47 & 0.645 & 1.00 \\
$\mathrm{~A} \times \mathrm{C}$ & -6.775 & -3.388 & 0.284 & -11.94 & 0.000 & 178.50 \\
$\mathrm{~A} \times \mathrm{T}$ & 1.501 & 0.751 & 0.283 & 2.65 & 0.018 & 178.78 \\
$\mathrm{~B} \times \mathrm{C}$ & -6.305 & -3.153 & 0.280 & -11.24 & 0.000 & 180.50 \\
$\mathrm{~B} \times \mathrm{T}$ & 1.533 & 0.767 & 0.280 & 2.74 & 0.015 & 180.78 \\
$\mathrm{C} \times \mathrm{T}$ & -0.0612 & -0.0306 & 0.0214 & -1.43 & 0.173 & 1.00 \\
\hline
\end{tabular}

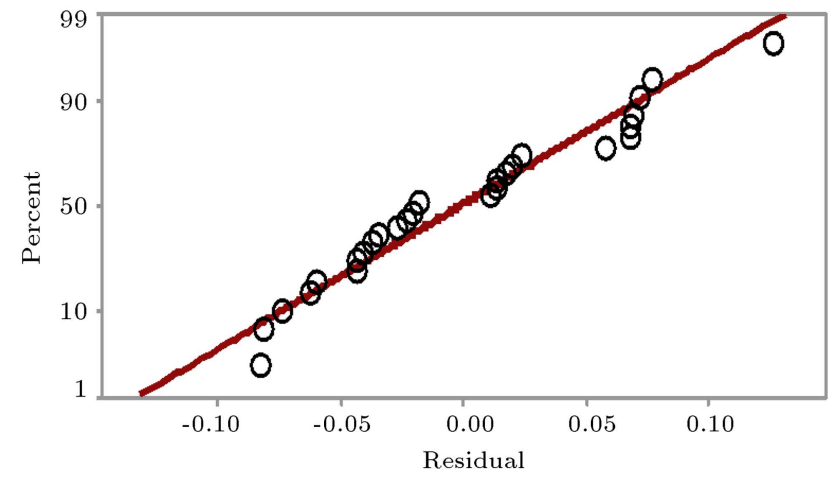

Figure 9. Normal probability plot for the $f_{r}(\mathrm{MPa})$.

In practice, a balanced or nearly balanced design with a large number of observations does not significantly affect the residuals (the difference between the observed and fitted response variables) if departed moderately from a straight line or normality [13]. Hence, the normally distributed residual from the analysis is required for a balanced design. As shown in Figure 9, the residuals generally follow a straight-line pattern, hence no evidence of non-normality or unknown variables in the model. Furthermore, in a designed experiment, the order of observations affects the response variable if the residuals fluctuate in a random pattern around the center line [13]. The result versus order for the response variable, as shown in Figure 10, exhibited a randomly scattered pattern about zero, hence no evidence of the correlation among the error terms.

\subsection{Effects of continuous variables on the response value (flexural strength)}

Following the fitted model generation based on the stored model, Figure 11 shows the main results of continuous variables on the response variable $\left(f_{r}\right)$. According to Figure 7, the constant variables influenced the response variable because the plotted lines were not

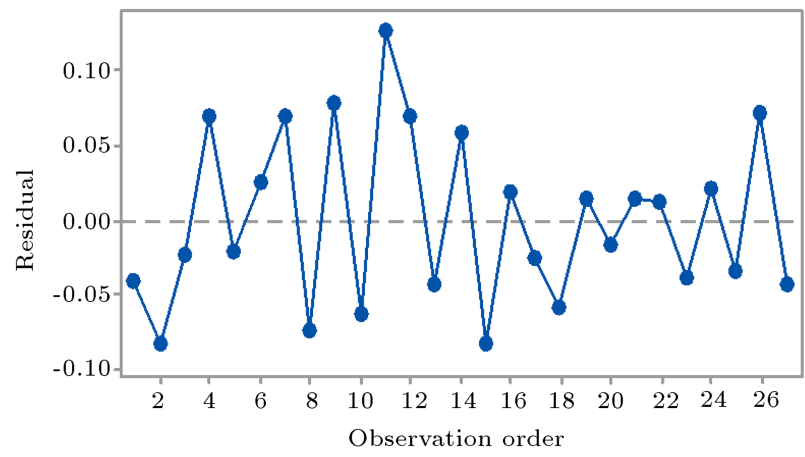

Figure 10. Residual versus order plot.

horizontal [13]. Furthermore, as observed, a decrease in the values of $A, B$, and $C$ resulted in increased resistance of the concrete beam against bending under the applied load. This measure accelerates the geopolymer paste setting time, boosts the geopolymerization process, compacts the microstructures, minimizes the geopolymer matrix pores, and consequently leads to higher flexural strength performance $[8,37]$. There was about 11-29\% decrease in the water-to-geopolymer solid ratio as the alkaline liquid-to-binder ratios in the mixes decreased from $0.62-0.42$ for M $25-\mathrm{M} 40$ concrete grades. Furthermore, a concrete mix with a low waterto-binder ratio and high cement content exhibited decreased strength in case of using higher aggregate particles [12]. Therefore, a more insufficient waterto-binder ratio would not result in higher strength in this mix at later ages, the reason for which could be associated with the shrinkage that induced stresses and restrained aggregate particles, hence cement-paste cracking and loss of the cement-aggregate bond [12] which are attributed to a lower binder to aggregates ratio with increasing flexural strength obtained in this study. In addition, Kaplan [38] reported that the mechanical interlocking and crack-arresting capacities of 


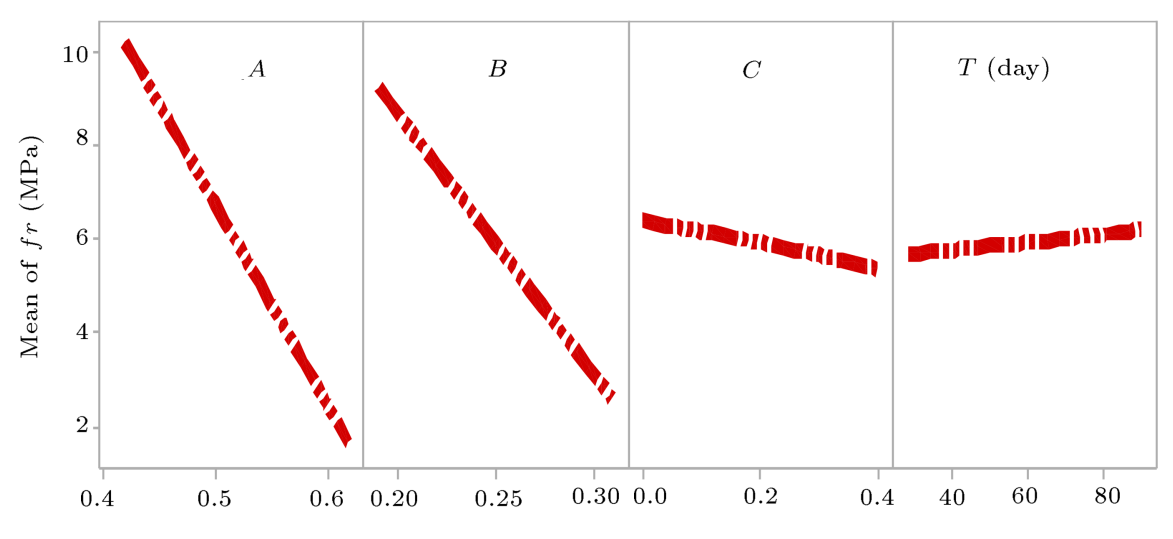

All displayed terms are in the model

Figure 11. The main effect of continuous variables on the flexural strength.

coarse aggregates significantly contributed to increased compressive and tensile strength of concrete rather than flexural strength. Here, the binder-to-aggregate ratio is a secondary factor in the flexural strength of concrete [38]. However, longer curing times were attributed to the higher resistance of concrete beam against bending under the applied load rather than the shorter curing times. Upon comparing the effects of each continuous variable on the response variable, the results in Figure 11 indicate that both $A$ and $B$ exhibited a higher magnitude of the main effect than $C$ and $T$. Alkaline liquid to binder $(A)$ and binder to aggregate $(B)$ rates yielded a more significant difference between the vertical positions of the plotted points.

\subsection{Establishment of desirable response value and operating conditions}

3.4.1. Operating conditions of $B$ and $A$ on the flexural strength

Figure 12 shows the flexural strength with the binderto-aggregate and alkaline liquid-to-binder proportions following the model equation. In contrast, both CCA/GGBFS ratio and curing time were kept constant. Figure 12 illustrates the visualized effect of both $B$ and $A$ on both $2 D$ contour lines of the binder.

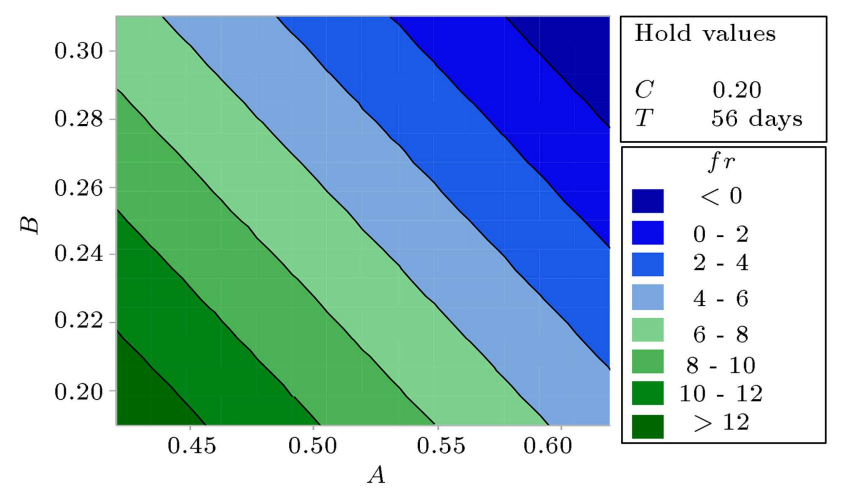

Figure 12. Interaction between $B$ and $A$ on the flexural strength $\left(f_{r}, \mathrm{MPa}\right)$.
According to Figure 12, a higher flexural strength was attributed to the lower binder-to-aggregate and alkaline liquid-to-binder ratios at a constant of $80 \%$ GGBFS on day 56 of curing. However, any change in the hold values alters the shape patterns of the continuous variables. As shown in Figure 12, the darkest green area indicates the contour, which yields the highest flexural strength (12 MPa). Therefore, the resistance of the concrete beam against bending under the applied load can be maximized to around $0.20,0.45$, 0.20 , and 56 for $B, A, C$, and $T$, respectively.

\subsubsection{Operating conditions of $C$ and $A$ on the flexural strength}

The effect of the interaction between $C$ and $A$ on the flexural strength of the concrete beam is illustrated in Figure 13. It was also revealed that the lower the proportions of both $C$ and $A$ in the concrete mix, the higher the flexural strength, while keeping both $B$ and $T$ constant at 0.23 and 56 , respectively. The most upper flexural strength $(15 \mathrm{MPa})$ was obtained around $70 \%$ GGBFS and 0.42 of $A$ for the concrete mix at the constant valu es of 0.23 and 56 for $B$ and $T$, respectively. Since the $2 \mathrm{D}$ contour plot is indicative of the minimax response surface [13], these proportions

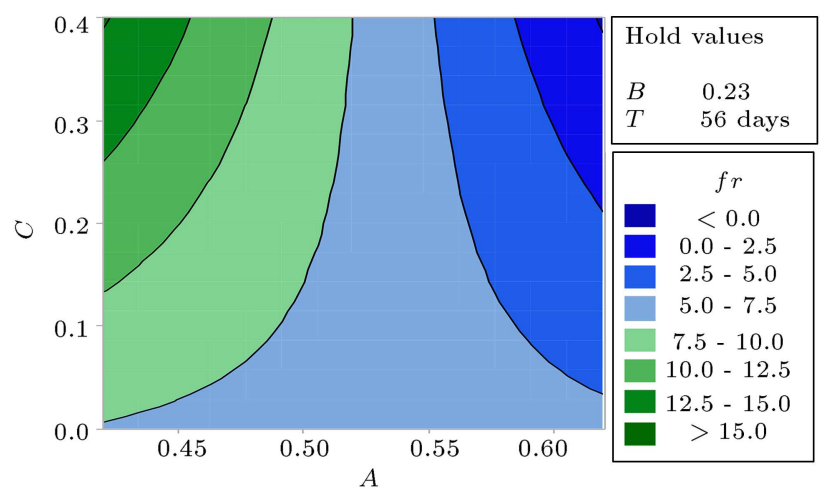

Figure 13. Interaction between $C$ and $A$ on the flexural strength $\left(f_{r}, \mathrm{MPa}\right)$. 


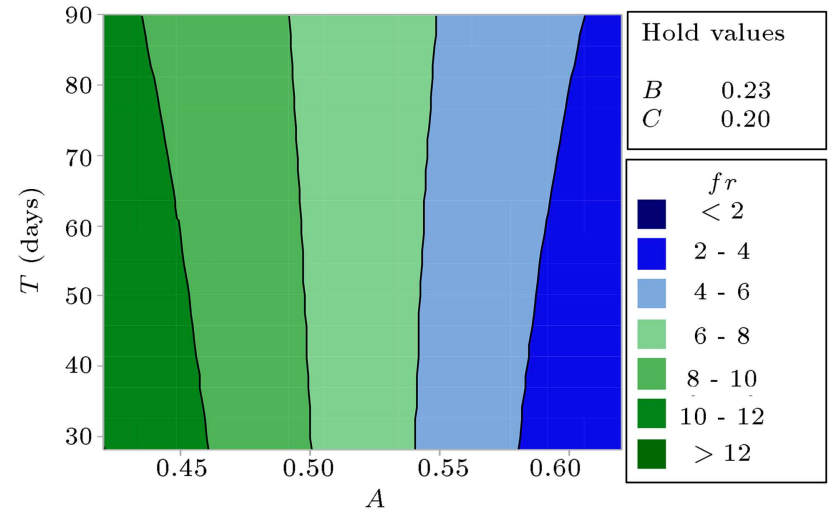

Figure 14. Interaction between $T$ and $A$ on the flexural strength $\left(f_{r}, \mathrm{MPa}\right)$.

can be selected for a flexural strength of concrete incorporating natural pozzolans and targeting $15 \mathrm{MPa}$.

\subsubsection{Operating conditions of $T$ and $A$ on the flexural strength}

The operating conditions of both $T$ and $A$ on the flexural strength, as given in Figure 13, pointed to almost the same interaction with the results presented in Figure 12. Figure 14 shows that a long curing time $(T)$ and a low alkaline liquid to binder ratio $(A)$ increased the flexural strength of concrete. The strength was maximum (12 MPa) around days 30-56 of curing and 0.45 of $A$, holding both binder to aggregate ratio $(B)$ and $C$ at 0.23 and 0.20 constant.

\subsubsection{Operating conditions of $C$ and $B$ on the flexural strength}

Figure 15 shows the interaction between $C$ and $B$ concerning the flexural strength of the concrete beam. It was revealed that a low proportion of binder-toaggregate $(B)$ increased the resistance of the concrete beam against bending at the constant values of both $T$ and $A$. As reported earlier in Figure 11, the ratio $(C)$ of binders had no significant effect on the yield of flexural strength, thus confirming the results given in Figure 15. Therefore, the highest flexural strength (10 MPa), as

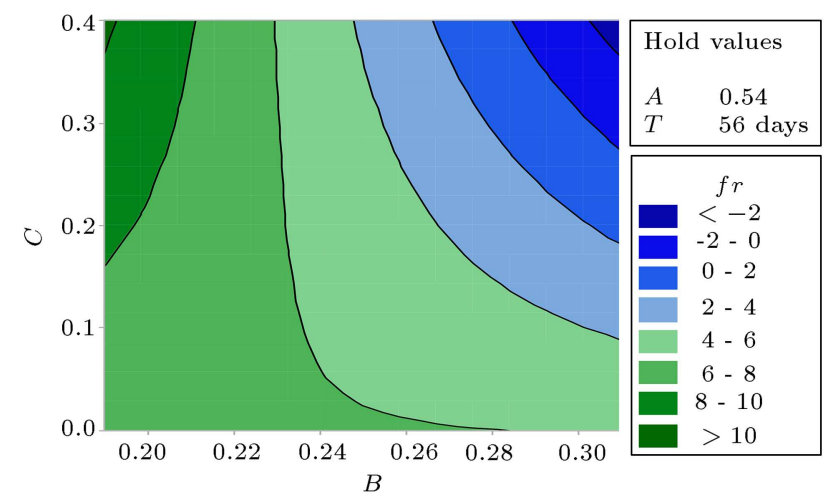

Figure 15. Interaction between $C$ and $B$ on the flexural strength $\left(f_{r}, \mathrm{MPa}\right)$. shown in the left-upper region (darkest green area) in Figure 15, was yielded around 0.40 of $C$ and 0.20 of $B$, holding both $A$ and $T$ at the constant values of 0.54 and 56 , respectively. Therefore, the interactive effects of the continuous variables $(A, B, C$, and $T$ ) on the flexural strength of concrete beam incorporated with SCMs using both 2-D contour lines would be conducive to not only the optimization of the mix design proportions for obtaining target and maximum flexural strength of GPC but also the implementation of future studies.

\subsection{Optimization}

Figure 16 presents the optimization results of the flexural strength based on the combination of desirability functions into composite desirability (D) in the stored models. Minitab 17 statistical software displays a global solution by default, which is the best of all local solutions. The universal solution combines the variable settings to obtain the desired responses. The desirability of each variable predicts how close the expected response is to the target requirements, and it is measured on a scale of 0 to 1 . The vertical brown and horizontal blue lines, as shown in Figure 16, signified a current setting and a current response value, respectively. The current setting showed alkaline liquidto-binder ratio $(A)$, binder-to-aggregate ratio $(B)$, $\mathrm{CCA} /(\mathrm{CCA}+\mathrm{GGBFS})$ ratio $(C)$, and curing time ( $T$, day) as $0.42,0.23,0.20$, and 90 , respectively. It is shown that a current response (an optimized flexural strength of $10.52 \mathrm{MPa}$ ) could be obtained only at the minimized values of $A, B$, and $C$ and a maximized value of $T$. In this respect, this current response demonstrated that $A, B, C$, and $T$ obtained their ideal settings which could significantly optimize the flexural strength at these absolute values. Therefore, the flexural optimization results for the concrete strength supported a relationship, as illustrated in Eq. (5), such that $D=1$ because the response $r(10.52 \mathrm{MPa})$ was higher than the target $(T, 7.40 \mathrm{MPa})$. As given in Eq. (8), this relationship was employed to affirm the validity of the optimization parameters. The result yielded a flexural strength of 10.52 MPa, thus ensuring the accuracy of the optimized equation.

\subsection{Relationship between experimental and optimized flexural strengths}

Through the fitted linear regression equation, the relationship between the optimized flexural strength $\left(O f_{r}\right)$ and experimental flexural strength $\left(E f_{r}\right)$ is given in Figure 17. The results indicated that there was a strong correlation between the optimized flexural and experimental flexural strength. The coefficient of determination $\left(R^{2}\right)$ also demonstrated that the model was $99.6 \%$ fit to predicting the relationship between $O f_{r}$ and $E f_{r}$ at both $95 \%$ confidence and predictive intervals. Furthermore, the standard distance (S) of 


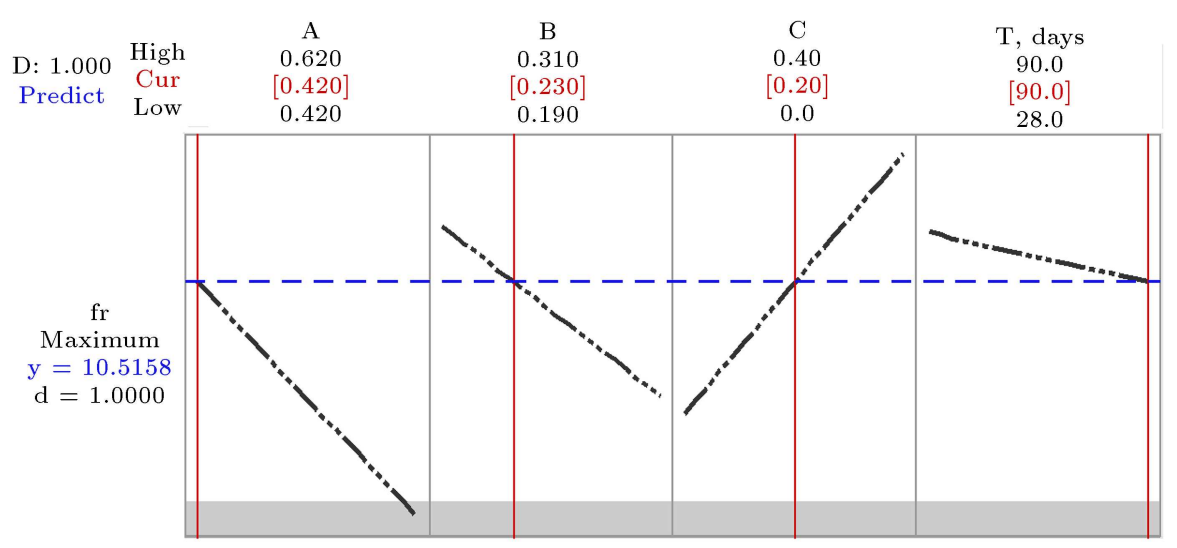

Figure 16. Optimization results for the flexural strength $\left(f_{r}, \mathrm{MPa}\right)$.

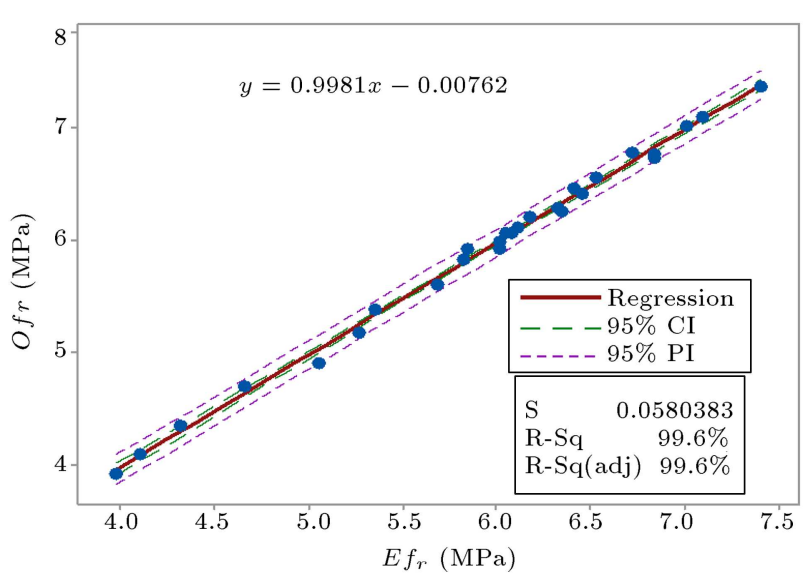

Figure 17. Relationship between $O f_{r}$ and $E f_{r}$.

the response demonstrated that the data values were concentrated on the regression line; hence, the data values fitted the regression line and the model equation could significantly predict the response [39].

\section{Conclusions}

The present study evaluated the flexural strength of the concrete modified by both Corn Cob Ash (CCA) and Ground Granulated Blast Furnace Slag (GGBFS). The obtained results were compared with those of the control samples Portland Cement Concrete (PCC). In this study, while the flexural strength was maximized, the mix proportion properties were minimized. Finally, the following conclusions were made:

i. There was about $2-15 \%, 8-20 \%$, and $5-16 \%$ increase in the compressive strength on day 28 of curing when GGBFS was replaced with 0-40 wt\% CCA for concrete grades 25, 30, and 40, respectively, compared with the control (conventional) concrete;

ii. On day 28 of curing, there was about $1-26 \%, 10-$ $14 \%$, and $2-10 \%$ increase in the flexural strength $\left(f_{r}\right)$ of Geopolymer Concrete (GPC) as the percentage substitution of $\mathrm{CCA}$ in the mix increased from $0-40 \%$ compared with PCC for concrete grades 25, 30, and 40, respectively;

iii. There was about $30 \%$ increase in the flexural strength when the strength was optimized at 0.42 , $0.23,0.20$, and 90 for $A, B, C$, and $T$, respectively;

iv. There was a strong correlation between the experimental flexural and optimized flexural strength.

Given the limitations, this study suggests the benefits of focusing on three prospective solutions for further research. First, the model equation can be beneficial to the optimum design proportions of concrete beams, thus reducing the cost and time of carrying out laboratory experiments. Second, CCA and GGBFS utilization offers higher flexural strength than Portland Limestore Cement (PLC). Third, CCA and GGBFS can be used as natural pozzolans for further application.

\section{Acknowledgement}

The authors acknowledge the Covenant University Centre for Research, Innovation, and Discovery (CUCRID) for providing fund and conducive environment for carrying out the study.

\section{References}

1. Bouaissi, A., Li, L., Abdullah, M., and Bui, Q. "Mechanical properties and microstructure analysis of FA-GGBS-HMN based geopolymer concrete", Construction and Building Materials, 210, pp. 198-209 (2019).

2. Aiken, T.A., Kwasny, J., Sha, W., and Soutsos, M.N. "Effect of slag content and activator dosage on the resistance of fly ash geopolymer binders to sulfuric acid attack", Cement and Concrete Research, 111, pp. 2340 (2018).

3. Mark, O.G., Ede, A.N., Olofinnade, O., Bamigboye, 
G., Okeke, C., Oyebisi, S.O., and Arum, C. "Influence of some selected supplementary cementitious materials on workability and compressive strength of concretea review", IOP Conference Series: Materials Science and Engineering, 640, p. 012071 (2019).

4. Kathirvel, P. and Kaliyaperumal, S.R.M. "Performance of alkali-activated slag concrete under aggressive environment", Scientia Iranica, 25(5A), pp. 24512460 (2018).

5. Akinwumi, I.I. and Aidomojie, O.I. "Effect of corncob ash on the geotechnical properties of lateritic soil stabilized with Portland cement", International Journal of Geomatics and Geoscience, 5(3), pp. 375-392 (2015).

6. Oyebisi, S., Ede, A., Olutoge, F., and Omole, D. "Geopolymer concrete incorporating agro-industrial wastes: Effects on mechanical properties, microstructural behaviour and mineralogical phases", Construction and Building Materials, 256, p. 119390 (2020).

7. Guangwei, L., Huajun, Z., Zuhua, Z., and Qisheng, W. "Effect of rice husk ash addition on the compressive strength and thermal stability of metakaolin based geopolymer", Construction and Building Materials, 22, pp. 872-881 (2019).

8. Samad, S., Shah, A., Lambachiya, M.C., and Desai, S.B. "Strength development of binary cement concrete, using Pulverized Fly Ash (PFA) under various curing conditions", Scientia Iranica, 26(2A), pp. 615-624 (2019).

9. Khan, S.U., Nuruddin, M.F., Ayub, T., and Shafiq, N. "Effects of different mineral admixtures on the properties of fresh concrete", Scientific World Journal, 986567, pp. 1-11 (2014).

http://dx.doi.org/10.1155/2014/986567

10. Davidovits, J. "High-alkali cement for 21st century concretes", in Concrete Technology, Past, Present and Future, Proceedings of V, Mohan Malhotra Symposium, American Concrete Institute, 144, pp. 383-397 (1994).

11. Onoue, K. and Bier, T.A. "Optimization of alkaliactivated mortar utilizing ground granulated blastfurnace slag and natural pozzolan from Germany with the dynamic approach of the Taguchi method", Construction and Building Materials, 144, pp. 357372 (2017).

12. Neville, A.M., Properties of Concrete, 5th Edition, Pearson Education Limited. England (2011).

13. Myers, R.H., Montgomery, D.C., Anderson-Cook, C.M., Response Surface Methodology: Process and Product Optimization using Designed of Experiments, 3rd Edition, John Wiley and Sons, Inc. New Jersey (2009).

14. Montgomery DC Design and Analysis of Experiments, 6th Edition. John Wiley and Sons, Inc., New York (2005).

15. Alsanusi, S. and Bentaher, L. "Prediction of compressive strength of concrete from early age test result us- ing design of experiments (RSM)", International Journal of Civil and Environmental Engineering, 9(12), pp. 1559-1563 (2015).

16. Dai, C., Wu, A., Qi, Y., and Chen, Z. "The optimization of mix proportions for cement paste backfill materials via Box-Behnken experimental method", Journal of Institute of Engineering (India Series D), 100(2), pp. 307-316 (2019).

17. Liu, H., Liu, S., Wang, S., Gao, X., and Gong Y. "Effect of mix proportion parameters on behaviours of basalt fibre RPC based on Box-Behnken model", Applied Science, 92031 (2019).

18. Ramkumar, B.G., Barmavath, S., and Nagaraju, K. "Application of response surface methodology for optimization of alkali activated slag concrete", International Journal of Science, Development and Research, 2(3), pp. 35-47 (2017).

19. British Standard EN 196-3, Method of Testing Cement: Physical Test, BSI, London (2016).

20. British Standard EN 196-6, Methods of Testing Cement: Determination of Fineness, BSI, London (2018).

21. British Standard EN 15167-1, Ground Granulated Blast Furnace Slag for Use in Concrete, Mortar and Grout: Definitions, Specifications and Conformity Criteria, BSI, London (2006).

22. British Standard EN 450-1, Pozzolan for Use in Concrete: Definitions, Specifications and Conformity Criteria, BSI, London (2012).

23. British Standard EN 196-2, Methods of Testing Cement: Chemical Analysis of Cement, BSI, London (2016).

24. British Standard EN 12620, Aggregates from Natural Sources for Concrete, BSI, London (2013).

25. Rajamane, N.P. and Jeyalakshmi, R., Quantities of Sodium Hydroxide Solids and Water to Prepare Sodium Hydroxide Solution of Given Molarity for Geopolymer Concrete Mixes, Indian Concrete Institute Technical Paper, SRM University, India (2014).

26. Oyebisi, S., Ede, A., Olutoge, F., and Olukanni, D. "Assessment of activity moduli and acidic resistance of slag-based geopolymer concrete incorporating pozzolan", Case Studies in Construction Materials, 13, e0039456 (2020).

27. British Standard EN 206, Concrete Specifications, Performance, Production and Conformity, BSI, London, (2016).

28. British Standard 1881-125, Testing Concrete: Methods for Mixing and Sampling Fresh Concrete in the Laboratory, BSI, London (2013).

29. British Standard EN 12390-2, Testing Hardened Concrete: Making and Curing for Strength Tests, BSI, London (2019).

30. British Standard EN 12390-3, Testing Hardened Concrete: Compressive Strength of Test Specimens, BSI, London (2009).

31. British Standard EN 12390-5, Testing Hardened Con- 
crete: Flexural Strength of Test Specimens, BSI, London (2019).

32. Derringer, G. and Suich, R. "Simultaneous optimization of several response variables", Journal of Quality Technology, 12, pp. 214-219 (1980).

33. Chen, W. and Brouwers, H. "The hydration of slag, Part 1: reaction models for alkali-activated slag", Journal of Materials Science, 42, pp. 428-443 (2007).

34. Khale, D. and Chaudhary, R. "Mechanism of geopolymerization and factors influencing its development: a review", Journal of Materials Science, 42, pp. 729-749 (2007).

35. Asadzadeh, S. and Khoshbayan, S. "Multi-objective optimization of influential factors on the production process of foamed concrete using Box-Behnken approach", Construction and Building Materials, 170, pp. 101-110 (2018).

36. Oyebisi, S., Ede, A., Olutoge, F., and Ogbiye, S. "Evaluation of reactivity indexes and durability properties of slag-based geopolymer concrete incorporating corn cob ash", Construction and Building Materials, 258, 119604 (2020).

37. Wan, X., Hou, D., Zhao, T., and Wang, L. "Insights on molecular structure and micro properties of alkaliactivated slag materials: A reactive molecular dynamics study", Construction and Building Materials, 139, pp. 430-437 (2017).

38. Kaplan, M.F. "Flexural and compressive strength of concrete as affected by the properties of coarse aggregates", Journal of American Concrete Institute, 55, pp. 1193-1208 (1959).

39. Oyebisi, S.O., Ede, A.N., and Olutoge, F.A. "Optimization of design parameters of slag-corncob ashbased geopolymer concrete by the central composite design of the response surface methodology", Iranian Journal of Science and Technology, Transactions of Civil Engineering, 45(1), pp. 27-42 (2021).

\section{Biographies}

Solomon Oyebisi obtained his BTech in Civil Engineering from Ladoke Akintola University of Technology, Ogbomoso, Nigeria in 2008. He also obtained his MSc and $\mathrm{PhD}$ in Civil Engineering from University of Ibadan, Ibadan and Covenant University,
Ota, Nigeria in 2015 and 2020, respectively. His research interests include valorization of agro-industrial wastes as supplementary cementitious materials used in producing Green Concrete, structural engineering, and earthquake and seismic analysis. He has published over 50 articles in reputable journals and conferences. Currently, he is working as a faculty member and a researcher at Covenant University, Ota, Nigeria.

Hilary Owamah obtained his BEng in Civil Engineering from Federal University of Technology, Owerri, Nigeria in 2006. He obtained his MEng and $\mathrm{PhD}$ in Environmental Engineering from University of Port-Harcourt, Port-Harcourt and University of Benin, Benin in 2011 and 2016, respectively. His research interests include solid waste management and engineering, geo-environmental engineering, and water suppl engineering. He has published over 50 articles in reputable journals and conferences. He was the former Head of Civil and Environmental Engineering Department, Delta State University, Nigeria. Currently, he is working as an Associate Professor of Civil and Environmental Engineering at Delta State University, Nigeria.

Anthony Ede has a Laurea (combined BSc and $\mathrm{MSc}$ ) in Civil Engineering with specialization in structures from the "Alma Mater Studiorum" University of Bologna, Italy in 2001. He received his $\mathrm{PhD}$ in Composite Materials for Civil Structures in 2008 from the University of Sorrento, Lecce, Italy. His current research interests include sustainable structural systems, sustainable construction materials, structural health monitoring methods and techniques, mechanical and chemical characterizations, dynamic-based structural damage methods, use of natural fiber in structural strengthening, novel geopolymer concrete, causes of building collapse, behavior of natural fiber, and fiber-reinforced polymer composites for structural applications. He has published over 100 articles in reputable journals and conferences. He is the Head of Civil Engineering Department, Covenant University, Nigeria. Currently, he is working as a Professor of Structures and Sustainable Construction Materials at Covenant University, Nigeria. 